\title{
8. Public laboratory: Play and civic engagement
}

\author{
Jessica Breen, Shannon Dosemagen, Don Blair, and Liz Barry
}

\begin{abstract}
This chapter explores the potential of play in relation to community-based civic science research using DIY scientific tools made possible by the Public Laboratory for Open Technology and Science (Public Lab). It discusses projects and approaches that the Public Lab has developed since its launch in 2010 to facilitate meaningful civic science collaboration. This includes a focus on narrative forms to connect participants to science research, relying on a spontaneous, playful emergence of collaborative activity rather than pre-developed forms of gamification to allow the incentives for participation to be intrinsic to the nature of the activity. This transforms the practice of scientific research and civic engagement into something that is both effective and ultimately enjoyable and productive, for all of those involved.
\end{abstract}

Keywords: Public Lab, civic science, playful participation, civic engagement, DIY, community

Right before we reach the end of LA-23, a long stretch of road through Plaquemines Parish, Louisiana, we turn off into the parking lot of a marina. The drive from New Orleans to Venice took us through a landscape of rural agriculture, refineries, and tight-knit communities and into one of the epicenters of the oil spill cleanup. We'd spent the drive cutting up two-liter soda bottles, installing the Canon Hack Development Kit (CHDK) on a Canon camera and guessing what it would be like when we got to our final destination, the Chandeleur Islands. It had only been a few days since we had listened to the news of the Deepwater Horizon rig explosion. Now, it was 9 May, and after endless days of navigating work,

Glas, R., S. Lammes, M. de Lange, J. Raessens, and I. de Vries, eds. 2019. The Playful Citizen. Civic Engagement in a Mediatized Culture. Amsterdam: Amsterdam University Press. DOI: $10.5117 / 9789462984523 / \mathrm{CHO} 8$ 
confusion, and media, we heard that the first signs of oil were headed toward the Chandeleur Islands. We were meeting a charter boat captain who had volunteered to take the three of us-equipped with a weather balloon, helium tank, duct tape, and other miscellaneous parts- to one of his favorite sport fishing spots out there. He wanted to see the oil's impact, too.

We motored slowly down the long canal that would lead us into the Gulf of Mexico. We passed trawlers converted into oil skimming vessels, the remnants of pipeline structures, and the quickly disappearing Breton Sound, finally making our way into the relatively calm waters within the Chandeleur Island chain. Over the side of the boat, coagulated red objects floated past, swimming among the oily sheen. A foul smell hung in the air, leaving us all with aching eyes and heads by the time we returned to shore later in the day. We spent the afternoon navigating the coastline, considering wading to shore (but not feeling comfortable getting into the alien-looking water), and playing with the balloon mapping materials we brought along. With a toolkit that consisted of one large balloon, a newly constructed soda bottle rig, kite reel, a camera and gloves, we experimented with different tie-off techniques on the balloon, duct taped shut a hole that formed in the rubber of the balloon, and finally launched it into the perfectly calm afternoon. Floating 1,500 feet above us, well below the official 3,000 foot floor that had been imposed on flyovers that week, we swapped stories, watched pelicans and helicopters flying on and off the island and captured images that would later illustrate a story of the surreally beautiful devastation that was unfolding around us.

Play is an activity that is positively viewed by the player, self-motivated, freely chosen, and actively engaging (Garvey 1990). This concept of play extends back to what play meant to us in an educational context when we were young children, i.e. exploration and experimentation and figuring out how to engage with the space you occupy in new ways. We construct this chapter based on two central questions: how do we bring play into civic engagement? And how do we come to engage as a community of civic science practitioners in a space that requires us to constantly re-imagine play through exploration? 


\section{A brief history of the Public Laboratory for Open Technology and Science}

In the spring of 2010, NGOs, Gulf Coast residents, and members of GrassrootsMapping.org, coalesced to collect over 100,000 aerial images of the Deepwater Horizon disaster. Access to the coast was restricted in the aftermath of the oil spill, with local residents and journalists alike prevented from witnessing affected areas. There was much frustration due to the lack of volunteer opportunities to assist in oil clean-up, the media blackout, and difficulties accessing information vital to assessing ecological and public health risks. In response, the Public Laboratory for Open Technology and Science (Public Lab) formed to pilot a Do-It-Yourself method of collecting aerial imagery utilizing a helium-filled weather balloon and kites equipped with refurbished digital cameras housed in repurposed soda bottles to prevent them from fluttering in the wind. By flying these improvised rigs between 500 and 2,00o feet off the ground, we were able to capture high-resolution photos of the spill's effects and provide an inexpensive mechanism for grassroots community engagement and for monitoring both corporate and government response to the spill.

Since that time, Public Lab has expanded its toolset to include the development of DIY scientific tools to address a broad swath of environmental and social justice issues. These tools include a spectrometer, available as a kit on the Public Lab website, which was developed with the aim of identifying polyaromatic hydrocarbons in soil and sediment, but has been explored within the community for a variety of other further uses. The Public Lab community has also developed a 'thermal flashlight' for detecting thermal leaks, modified Roombas that paint with light to map indoor air pollutants like formaldehyde, devised hydrogen sulfide detectors that make novel use of photographic paper to sense emissions near hydro-fracking sites, and designed near-infrared cameras that produce images of plant health. We continually work to expand our articulation of community-based participatory models of science-based environmental engagement, adapting and refining our DIY research tools within a socially and politically aware context (Dosemagen, Warren, and Wylie 2011).

\section{Why so serious? Intersections of play and civic engagement}

Within Public Lab the intersection of play and civic engagement takes different forms. It can be found in our engagement with the broader citizen science community as we choose to relate our work in both narrative and visual 
formats, including the research notes and videos on the community website and the illustrated guide to balloon mapping included in our balloon kits. It is also to be found in the very tools we use and the means through which they are created. Science is, at its heart, a creative, collaborative process. It is advanced as individuals question their world, design experiments to challenge assumptions, and share their results with a community of other thinkers, who, in turn, question, experiment, and share their findings. Employing multiple modes of learning helps to engage a broader transect of people and expands the Public Lab community by rendering complex information accessible to many different types of researchers and learners. Likewise, the creative repurposing of everyday items as scientific tools, along with the collaborative nature of tool creation, helps return the scientific process to its roots as a collaborative community endeavor (Latour and Woolgar 1979).

\section{Bringing play back into science: Narrative forms of scientific research and engagement}

The purpose of the Public Lab process and tools is, fundamentally, to tell stories (de Certeau 1984). We believe that narrative forms of scientific research and engagement allow individuals to better connect to their topic and each other, thus the toolkit of civic science should, in the ethos of Public $\mathrm{Lab}$, create an opening for people to develop a narrative process around an exploration that they are undertaking. The Public Lab community embeds technologies themselves in a narrative - a set of possible uses, which enable specific inversions of power in communities with environmental concerns. This is not just 'balloon mapping,' but 'grassroots satellite photography'it matters who does it and why. For example, Public Lab created a DIY spectrometer that has been distributed to over 3,000 people around the world. The process of engaging with the tool has become one of creating a community that experiments, explores, and learns together in all stages of the process. Extending the range of your vision by sending cameras up thousands of feet on a balloon, connected to you by a tenuous 'optic nerve' of kite string (which lets you hear and feel the wind itself through its vibrations), and exploring an area from a new perspective is just one way Public Lab members playfully reconfigure technology to suit their needs. Tools created for civic science practices are ones that, at the root, require us to question both our social and physical boundaries. Maps created by the community with these images allow for a joint process of transcribing new narratives into the images. Questions can be developed about preconceived 
ideas of state instituted boundaries such as language, composition of ethnic populations, ideas of urbanity, and physically segregating markers.

Creating narrative layers in the process of civic science tool development and use can also help to connect us to the longer running, potentially generational narrative of engagement within our neighborhoods. The collaborative art of using tools that allow a community to investigate, connects us to the past while serving to help us formulate future means of engagement and management with our environment. An example of this type of engagement with civic science tools can be demonstrated by community members working around the Gowanus Canal in Brooklyn, New York. They have used aerial mapping tools to link the past use of a site, through a narrative format, to future management and preservation efforts as a part of a larger community effort of remembrance and reconstituting ownership. As written in a research note on the Public Lab website:

The key reasons for interest in the site was that this particular lot had been identified as the sole remaining remnant of 'Marylander Hill,' described by historians as a grave site for early colonial settlers, slaves and War of Independence soldiers [...] Based on historical maps and recorded evidence [...] the 'Over My Dead Body' Mapping Team launched their 56" diameter red weather balloon from the nearby Gowanus Canal Conservancy's high tech Mission Control Center, home of GLAM (Gowanus Low Altitude Mapping) at 2nd Avenue and the Gowanus Canal [...] Looking at the photographs a couple of minutes later [...] a curious fact was uncovered by scrutinizing the high-resolution images: the cracks in the concrete-the 'grassroots' —-were telling a story. (Diegel 2012, n.p.)

The above case demonstrates that in civic science there is the potential to create engaging narrative to form a compelling story about the environment that gives a call to action. The 'Over My Dead Body' Mapping Team were able to support their argument that there was in fact a Revolutionary War cemetery located on Marylander Hill by using simple tools showing that the cracks in the concrete line up with the kind of soil settling one would expect to see in a cemetery. By incorporating problem identification, tool development, data collection and analysis, the Public Lab model can facilitate a feeling of involvement in one's space and environment through the transformative narrative of engagement (Blair et al. 2013). This process outlines key points relating to play in the form of questioning and creating new ideas and interpretations, but also holds formal engagement methods, such as the open source licensing that Public Lab uses as key to ensuring 
an exploratory environment that prides itself on allowing and encouraging reinterpretation and new discoveries. In detailing a process that asks people to think about how they can once again become engaged in the management and use decisions of their environment, the process provides a critical means for engaging at every step of the process.

In moving away from the classic model of citizen science, wherein individuals assist professional research scientists by submitting data points as part of a larger research project, some of the steps in the Public Lab process that allow deeper engagement include:

1) Engage people as fellow researchers, not subjects; the community is involved in all aspects of the project from question development, research design, and data collection to analysis;

2) Taking seemingly complex consumer technologies and with simple hacks, re-imagining them as instruments for data collection;

3) Build in social engagement and accountability as part of the process of play in civic science. For instance, aerial mapping, through a balloon attached to a kite string, links the process of data collection to the person holding the string, making that person visible and accessible;

4) Create collaborative workflows allowing people to continue working together after the balloon mapping is complete. Open source platforms such as Public Lab's MapKnitter.org allow people to work together to create a community-based map of their neighborhood;

5) Use open source to encourage the adaptation and reuse of Public Lab tools and methods and, in essence, ensure a safe space for people to collaboratively create and build locally modified tools which can then be adopted for grassroots investigations in diverse communities. ${ }^{1}$

\section{"Easy on the eyes": The role of the visual in civic science participation}

Public Lab embraces legibility and chooses to rely on people's intuitive visual fluency. This helps avoid jargon. Stylistically, engaging visual communication in Public Lab so far has ranged from sketched cartoons to pixelated, low-resolution graphics, with new genres cropping up all the time. Public Lab finds that there are several advantages to emphasizing informal

1 These points were first developed by Mathew Lippincott, Shannon Dosemagen, and Sara Wylie for a keynote at Rensselaer Polytechnic Institute's Triple Helix Technoscience as Activism conference on 28 June 2012. 
visualizations in our work. These advantages are found primarily in two realms: tool development processes and data structure design.

While many people would say the reimagining of science tools using reusable, recycled material is playful, an equal number of people may find that while it may be a fun form of play for the technologists, it is difficult for average people to participate. Part of the way Public Lab connects the knowledge of people with technological expertise to people with a placebased expertise is the use of illustrated instructional materials.

Public Lab is re-orientating the space of design, engineering, and collaboration (back) into a more legible and accessible place: a piece of paper. We have observed that open source software groups and scientists often erect barriers through prerequisite software/tools that they take for granted. Sketches can readily be posted to the Public Lab website via an emailed digital photo, allowing immediate community information sharing and feedback, and a continuous stream of documentation. Often the drawings and sketches assembled during the process of tool development find their way into an illustrated guide for the tool's use-Public Lab's preferred type of instruction manual.

Designing tools goes hand in hand with designing the data structures used for recording environmental information. Since most people find image-based data easier to directly understand with less interpretation (in contrast to a spreadsheet of numbers), drawings and raster images are central to how Public Lab communicates its research. Examples of image data include aerial photographs, aerial maps, video of a spectrum emitted by a chemical, time-lapse photo that captures thermal flashlight 'heat painting,' and videos of experimental setups and techniques. Therefore, Public Lab's model for tool development prioritizes users' ability to immediately produce visual output from their tool; Public Lab is less interested in sensors that are unable to be assembled without extended training and that create data which require a complicated series of steps between data acquisition and visualization. Public Lab prefers to start visual and stay visual.

\section{Research tool use: Play as a mode of interaction 'in the field'}

Engaging in research activities outside, in public places, can enable chance encounters with neighbors, business owners, workers, local authorities, school children - in short, a full cross section of the citizenry. Public Lab seeks to enable and encourage such serendipitous engagements with the way in which its tools are employed in the field. Public Lab's work invokes a sense of play in the very tools we employ in our mapping techniques-including 
outsized helium balloons and brightly colored kites with fuzzy tails. These objects radiate an aura of playfulness that facilitates engagement across boundaries of age, education, and politics. For these reasons, the Public Lab community prefers, for example, to use kites and balloons instead of the practice of using drones for aerial imaging, in which the operator is not easily apparent. In-person accountability and opportunities for building a coalition around the issues at hand are some of the most salient benefits of the socially grounded environmental research that Public Lab carries out.

That our aerial cameras are both launched from, and returned to, the group of people holding the string seems like an obvious point, however it has wonderful consequences - candid group shots of people young and old looking up, smiling and pointing at every mapping excursion. Taking field research to the next level, balloons and kites can even be launched from a boat, which invokes the spirit of intrepid and adventurous activities in the pursuit of science.

Once a year, the online Public Lab community meet at an event referred to as a Barnraising - a gathering of community members from across the country (and beyond) focused on the creation of a new tool. This is somewhat like a conference, but with an emphasis on 'doing stuff together' rather than just presenting papers and discussion. In the spirit of bringing a community together to collectively raise a structure such as a barn, Public Lab gather to develop tools, toolkits, supporting materials, such as guides and tutorials, to test the tools and to develop new research directions and projects. Participants represent a wide range of interests from technologists and designers to social scientists and community organizers. We hold these events at a 'field research station' out in the Louisiana Delta and we make sure to leave enough time every day to go outside and play.

Fieldwork respects the expertise of residents and workers who have a long-standing lived experience of the environment in question. Fieldwork enhances embodied knowledge, and builds a deeper connection with the environment and environmental issues. Fieldwork equips people to speak from a place of authenticity through personal experience. Building the equipment to capture a dataset that vouches for one's site observations adds a level of personal investment and this personal investment can add fuel to resulting advocacy campaigns.

\section{Reinventing the citizen science toolkit}

In the Public Lab community, sometimes the genesis of a new grassroots science technique is the identification of a specific need - the requirement 
for an airborne device that will capture certain frequencies of light, for example, or a DIY method for identifying contaminants in water-which inspires researchers to then begin brainstorming about designs for a new device. This is a creative and collaborative process, guided always by the constraints of producing a tool that is effective, inexpensive, and accessible. Often the most useful ideas emerge after initially taking design constraints lightly and proposing whimsical concepts that are later seen to contain the kernel of a more solid design.

Just as significant, however, is a tool design dynamic that follows a sort of reverse trajectory: researchers discover, or are presented with, a new tool, and after some thought realize that this existing tool might, with modification, be used to address an outstanding research problem. At Public Lab, we have witnessed this dynamic occur many times: people with an interest in the environment are shown a balloon mapping kit - the simple, but novel combination of a digital camera attached to a balloon - and ideas immediately begin to materialize ways in which the kit might be used to answer questions they already have. Most people do not realize that they would have any use for a DIY spectrometer until they see a demonstration of its ability to distinguish between different brands of olive oil or vintages of wine; their eyes light up, and they begin to imagine new uses for the device. At an event called LEAFFEST, parallel discussions of an airborne webcam device and the uses of aerial near-infrared (NIR) imagery playfully merged into a solid design for a new device: a near infrared webcam device capable of creating composite images on the fly.

\section{Who sets the rules of the game? Gamification vs. playful participation}

In describing the sort of interactions that Public Lab aims to facilitate in civic science, it is important to make a subtle, but significant distinction between a 'playful' approach to engagement, and the relatively recent trend toward the gamification of science (Deterding et al. 2011; Prestopnik and Crowston 2012). We find the gamification approach problematic. Akin to the manner in which crowd-sourcing is employed, gamification is typically carried out by experts invested in a particular research or behavior modification outcome; this outcome is often communicated to game participants, if at all, as an afterthought, resulting in game-players whose energies are being spent in service of an agenda which they are not fully aware of. Further, the incentive structure embedded in most games assumes that 'racking up points' will 
sustain enough interest and be sufficient incentive to induce participation; anyone who has played such a game more than a few times knows that these games can become tiresome (Iacovides et al. 2013; Mekler et al. 2013). Most importantly, because game players are typically not co-creators of the rules of the game and the associated assignment of points as rewards to various behaviors, they do not have an opportunity to embed their own values in the game's incentive structure. We find the potential distance between the values and goals of the game's designers, and the values and goals of game participants, to be a troubling aspect of typical gamification approaches.

In contrast, the playful approach embodied in Public Lab's activities seeks engagement through a spontaneous emergence of collaborative activity, in which the incentives for participation are intrinsic to the nature of the activity ("I am building a kite mapping kit so that I can see my neighborhood from 1000 feet up"); the result is a set of practices and tools that reflect precisely the priorities, interests, and values of each participant.

\section{Conclusion}

From launching a balloon over the Gulf of Mexico to sitting in front of a computer as a rainbow-like sample from a spectroscopy experiment appears, civic science creates a space for diverse groups of people to engage, collaborate, share and create. An oft-repeated mantra in the Public Lab community when encouraging people to post their first research note is "things going wrong are just as important as things succeeding." This notion stands in direct contrast with traditional practice in science and in education which does not usually publish failed results. ${ }^{2}$ Nevertheless, this is emblematic of Public Lab's approach. Accepting that mishaps and failures are important events for learning, empowers participants to be more open, free, playful, and creative in their scientific explorations, recognizing the point at which a change of direction is necessary, and making space for new research directions to emerge.

The open source, collaborative set of practices that Public Lab uses allows for a continually growing space-one that is not typical of more traditional scientific institutions. Our agendas, research questions, and methods follow an open, grassroots, bottom-up approach, in opposition to

2 With the possible exception of the International Journal of Negative \& Null Results, established in 2012 to publish scientific work deemed unpublishable by other scientific journals because it was unsuccessful. 
traditional top-down, hierarchical dynamics. This is evidenced in the way in which changes to tool designs are valued in the community, where even the slightest contributions - such as a community user-suggested change from using cardboard to plastic stabilizers to fly a camera rig, based on experience in the field - ultimately develop into an improved, widely used research tool design.

Further, and most importantly, these collaborative practices ensure that the research activities in which Public Laboratory engages - practices which emerge from the myriad small and large contributions of a diverse community - always reflect the values, priorities, and preferred modes of interaction of the people that constitute its research community. This transforms the practice of scientific research and civic engagement into something that is both effective, and ultimately enjoyable and productive, for all of those involved.

\section{References}

Blair, D., J. Breen, S. Dosemagen, M. Lippincott, and L. Barry. 2013. Civic, citizen, and grassroots science: Towards a transformative scientific research model. In Accountability technologies: Tools for asking hard questions, eds. D. Offenhuber and K. Schechtner, 23-31. Vienna: Ambra Verlag.

de Certeau, M. 1984. The practice of everyday life. Berkeley, CA: University of California Press.

Deterding, S., D. Dixon, R. Khaled, and L. Nacke. 2011. From game design elements to gamefulness: Defining "gamification". In Proceedings of the 15 th international academic MindTrek conference: Envisioning future media environments, Tampere, September 28-30, 2011, 9-15. New York: ACM.

Diegel. E. Raising the dead: Grassroots mappers help look for America's first veterans' cemetery. Public Lab. http://publiclab.org/notes/eymunddiegel/11-9-2012/raising-dead-grassroots-mapping-helps-look-america-sfirst-veteran-s-c.

Dosemagen, S., J. Warren, and S. Wylie. 2011. Grassroots mapping: Creating a participatory map-making process centered on discourse.Journal of Aesthetics and Protest 8, 217-228. http://joaap.org/issue8/GrassrootsMapping.htm. Garvey, C. 1990. Play: Enlarged edition. Boston, MA: Harvard University Press. Iacovides, I., C. Jennett, C. Cornish-Trestrail, and A. L. Cox. 2013. Do games attract or sustain engagement in citizen science? A study of volunteer motivations. CHI'z Extended Abstracts on Human Factors in Computing Systems, 1101-1106. New York: ACM. 
Latour, B., and S. Woolgar. 1979. Laboratory life: The construction of scientific facts. Princeton, NJ: Princeton University Press.

Mekler, E. D., F. Brühlmann, K. Opwis, and A. N. Tuch. 2013. Disassembling gamification: The effects of points and meaning on user motivation and performance. CHI'3 Extended Abstracts on Human Factors in Computing Systems, 1137-1142. New York: ACM.

Prestopnik, N., and K. Crowston. 2012. Purposeful gaming \& socio-computational systems: A citizen science design case. In Proceedings of the 17th ACM international conference on supporting group work, Sanibel Island, FL, October 27-31, 2012, 75-84. New York: ACM.

\section{About the authors}

Liz Barry is a founding member of the Public Laboratory for Open Technology and Science and is on the staff as Director of Community Development, guiding the group's unique combination of place-based organizing and online peer production. She teaches in Columbia University's graduate urban design department and speaks internationally on collaboration and urban environmental management. In 2015, the City of New York scaled TreeKIT - a project that Barry co-developed with Philip Silva to measure, map, and monitor street trees - up into a city-wide initiative called TreesCount! Barry was a Fellow at the Design Trust for Public Space on Five Borough Farm Phases II \& III (2012-14), and was named a Sunlight Foundation OpenGov Champion (2012).

Don Blair's work focuses on cooperative approaches to scientific research, development, and governance of technology in the areas of agroecology, regenerative agriculture, food and water security, and climate-related risk mitigation. He is currently a Research Associate at Edge Collective, where he is working to develop 'open infrastructure' for researchers and farmers contending with extreme or resource-constrained environments. He also co-organizes BARN, the Boston Agroecology Research Network. Don has recently served as Open Water Fellow at Public Lab; Research Affiliate at the Center for Civic Media at the MIT Media Lab; researcher and strategist at Food+Future; Citizen Science Liaison with FarmHack; and as an organizer for the Gathering for Open Agriculture Technology (GOAT). He holds a BA in Ancient Philosophy and an MSc in Physics from the University of Massachusetts Amherst. 
Jessica Breen is a fellow with the New Mappings Collaboratory, where her research uses social media and collaborative mapping techniques to understand the role of art and creativity in urban place-making. Jessica is an organizer with Public Lab, as well as being active in the OpenStreetMap and MapTime communities. Jessica is currently a Research Assistant with Mapshop, where she works with students, faculty, and community groups in the production of geographic representations and raising the critical mapping capacities. She holds an MSc in Environmental Studies and is pursuing a doctorate in Geography at the University of Kentucky. She can be found on Twitter @jessibreen.

Shannon Dosemagen is a founder and Executive Director of the Public Lab non-profit organization. In her current work with Public Lab, Shannon is interested in thinking through the use of community-collected data for the purpose of influencing policy around the environment and public health. She has an MSc in Anthropology and Nonprofit Management and is an Ashoka Fellow, a 2015-16 Harvard Berkman Center for Internet and Society Fellow, and a senior fellow of the Environmental Leadership Program. Shannon has contributed to articles in The Information Society (Special Forum, March 2014), Journal of Aesthetics and Protest (Issue 8, 2011) and Accountability Technologies: Tools for Asking Hard Questions (Springer 2013). She can be found on Twitter @sdosemagen. 